\title{
Retos criminológicos y jurídicos ante la violencia sexual contra la mujer en Cuba
}

\section{Criminological and legal challenges presented by sexual violence against women in Cuba}

"De mis sueños desciendo,

Volando vanse,

Y en papel amarillo

Cuento el viaje

Contándolo, me inunda

Un gozo grave:"

José Martí, Musa Traviesa.

Resumen

\section{Resumen}

El presente artículo de investigación resume algunos elementos de un estudio realizado sobre

Cómo citar

Ramos Portal, L. E. Retos criminológicos y jurídicos ante la violencia sexual contra la mujer en Cuba.

Constructos Criminológicos, 2(2). Recuperado a partir de https://constructoscriminologicos.uanl.mx/ index.php/cc/article/view/16

* Universidad de La Habana violencia sexual contra las mujeres en Cuba desde las perspectivas socio-criminológica y jurídica. Los datos expuestos, que refuerzan el contenido teórico, tienen como fuente el análisis de sentencias en materia penal y una Encuesta de Victimización Sexual. Las sentencias penales fueron publicadas en 34 Boletines del Tribunal Supremo Popular entre el año 1974 y el 2016 (último año de publicación), las cuales hacen referencia a 1182 delitos; la población estudiada estuvo compuesta por 113 sentencias contentivas de 166 delitos sexuales analizados en su contenido fáctico. La Encuesta de Victimización Sexual recabó datos sobre: percepción de seguridad, miedo ante la violencia sexual, condiciones que la favorecen, victimización sexual directa e indirecta, y reacción social.

La información obtenida constituye la primera fuente estadística de acceso público sobre la temática de la violencia sexual en Cuba y permitió arribar a conclusiones relevantes sobre el desarrollo de la victimogénesis, 
las características identitarias de víctimas y victimarios que son suficientes para el proceso penal y un estado de opinión sobre diversos factores sociales asociados; lo cual da respuesta a los objetivos metodológicos. De igual forma, se pudieron constatar las principales limitaciones en el campo jurídico y proponer modificaciones importantes a las normas penales en su contenido e interpretación.

Palabras clave: Adelitos sexuales, Derecho penal, perspectiva de género, victimización

\section{Abstract}

Some elements of a research work on sexual violence against women in Cuba from a socio-criminological and legal perspective are summarized in this article. The information provided, which reinforces the theoretical content, comes from an analysis of criminal sentences and from a Survey of Sexual Victimization. The said criminal sentences, published in 34 Bulletins of the People's Supreme Court between the years 1974 and 2016 (last year of publication), make reference to 1,182 offenses, whereas the studied population comprises 113 convictions for 166 sexual crimes whose factual content was studied. The Survey of Victimization collected data on perception of safety, fear of sexual violence and triggering factors, direct and indirect sexual victimization, and social reaction.

As the first publicly available statistical source about sexual violence in Cuba, these data point to important conclusions about the development of victimogenesis, the features that sufficiently define the identity of victims and victimizers to carry out a criminal process, and the prevailing state of opinion about various related social factors, all of which responds to our methodological goals. Likewise, they made it possible to both confirm the existence of limitations in the field of Law and suggest relevant modifications to the content and interpretation of criminal regulations.

Keywords: sexual crimes, Criminal Law, gender perspective, victimization

\section{INTRODUCCIÓN}

He descubierto cosas que no quería.

Ciertos estudios llevan a rincones del conocimiento que no siempre son bien recibidos. Se hallan en la zona intermedia entre el logro científico y el estupor. Gloria por el resultado académico y pena por confirmar hipótesis que desbrozan caminos de imperfección y sufrimiento humano.

Al indagar sobre la violencia sexual contra la mujer en Cuba, desde la perspectiva criminológica y jurídica, se descubren aristas de un fenómeno que exceden a su connotación social. Quizás sean el resultado de cinco siglos de cultura patriarcal, que tienden a solapar los desequilibrios de poder y las diferentes formas de violencia que se desarrollan en las relaciones internas de la sociedad cubana, expresadas en el fenómeno estudiado, pero también en el Derecho.

Luego del triunfo de la Revolución Cubana, específicamente durante el período transcurrido entre 1975 y 1989, se desarrollaron múltiples acciones y estudios sobre la mujer; con la implementación de políticas públicas sobre 
igualdad de derechos y educación sexual. Estos avances coincidieron y se materializaron en el proceso de institucionalización jurídica, o sea, en la mayor producción legislativa del período revolucionario; pero las leyes promulgadas, en su mayoría aún vigentes, como los Códigos de Familia, Civil y Penal o las de naturaleza procesal, entre muchas, no incorporaron la perspectiva de género; cuyo progreso inicia en la década de los 90 con una expresa propensión a la equidad y la visibilización de las violencias.

El desarrollo del enfoque de género coincidió con el progreso del pensamiento feminista y victimológico; supuso una renovación en las ciencias e impactó los estudios socio-criminológicos y en materia penal; tradicionalmente permeados por concepciones que limitaban la representación colectiva de la violencia en el imaginario popular, cultural y jurídico.

Es reconocido, en el ámbito internacional, que una de cada tres mujeres en el mundo sufre violencia física o sexual durante su vida y que, en América Latina y el Caribe, esta cifra alcanza el 29.8\%. Los actos de victimización más frecuentes consisten en forzarlas a tener relaciones o realizar un acto sexual humillante en contra de su voluntad, por temor a un desconocido o a su pareja. Estudios revelan que una de cada cinco niñas del mundo ha sufrido abusos sexuales durante su infancia; una de cada cuatro mujeres será abusada sexualmente antes de la edad de 18 años y una de cada seis ha vivido una violación o un intento de ella en su vida; más de la mitad antes de los 18 años, y el 22\% antes de los 12. (García-Moreno, 2005) (Bernabeu, 2017) (Tjaden \& Thoeness, 2000)
Los datos ofrecidos por fuentes internacionales son importantes para el direccionamiento de la política social y criminal, pero no son contrastables con las cifras en Cuba; debido a la fragmentación de las investigaciones y la insuficiencia de la información disponible en los centros vinculados a la operatividad del sistema penal.

Una pregunta general matiza la importancia de este trabajo. ¿Cuál es la situación de la violencia sexual contra las mujeres en Cuba? Pudiera suponerse que la violencia sexual o, al menos, los delitos sexuales denunciados y procesados pueden ser cuantificados con facilidad, sin embargo, no hay disponibilidad de datos, aún cuando existen varias instituciones que deben atender a este fenómeno dentro de su objeto de funcionamiento.

A modo de ejemplo se puede señalar que el Registro Central de Sancionados recoge solo los datos de las personas sancionadas cuando la pena impuesta constituye antecedente penal, según la legislación sustantiva vigente; su base de datos está signada por el nombre de los sancionados y no por el tipo de delitos en los que participan, por tanto, no maneja estadística real sobre la comisión de delitos sexuales y su reincidencia.

La Organización Nacional de Bufetes Colectivos guarda los datos sobre la contratación de servicios legales atendiendo a los códigos de los asuntos contratados, que tienen como referencia el costo de la representación en correspondencia con el marco sancionador de los delitos y la fase del proceso penal en la que se asume la defensa; pero no maneja o, al 
menos, no divulga estadísticas relacionadas con los tipos penales que motivaron la intervención de los letrados y letradas.

Los Institutos provinciales de Medicina Legal reportan mensualmente al Ministerio de Salud Pública los datos sobre los exámenes medicolegales realizados a las posibles víctimas de delitos sexuales, pero esta información no es vertida en el Anuario de Salud Pública o en publicaciones especializadas de dicho Ministerio.

La Fiscalía General de la República y el Tribunal Supremo Popular no aportan datos sistemáticos de posible consulta y su estadística interna se limita a los delitos procesados, radicados y sancionados, abarcando solo una parte de la violencia criminalizada y denunciada ante órganos del sistema penal. Ninguno de estos datos es de acceso público.

Se puede afirmar que, hasta el desarrollo de esta investigación, existían escasa información disponibles sobre victimización sexual en Cuba.

\section{MARCO TEÓRICO ESENCIAL}

La violencia, como fenómeno, tiene contornos indefinidos y sus manifestaciones se entrelazan de forma compleja. En este trabajo se tratan aspectos de la violencia sexual desde un enfoque crítico, con referencia a aquella que afecta a las mujeres, por constituir la mayor expresión de discriminación por razón del sexo y el género que se aprecia en el ámbito social y delictivo.
La violencia sexual contra la mujer consiste en el despliegue de una conducta humana individual o colectiva, a través de mecanismos de poder estructurales, culturales o personales, que se materializa en abusos, ataques, lesiones o amenazas u otros actos de discriminación por razón del sexo o el género, que se oponen a la voluntad expresa o tácita de las víctimas, menoscaban la sexualidad y representan una vulneración de los derechos sexuales y/o reproductivos femeninos, concebidos como derechos humanos.

Se ha de considerar mujer a toda persona del sexo femenino de cualquier edad; sea niña, adolescente, adulta o adulta mayor, sin distinción por el color de la piel, etnia, condición social o económica, creencias religiosas, orientación sexual o roles de género que desarrolle, discapacidad, origen territorial o cualquier otra circunstancia personal que implique lesión a la dignidad humana; o cualquier persona que dada su identidad de género se considere como mujer.

El elemento subjetivo predominante en el proceso de victimización sexual es la ausencia de consentimiento y de percepción de la violencia por parte de las víctimas. La ausencia de lesiones físicas en la víctima no es un indicador de anuencia o aprobación de la violencia. La minoría de edad, ciertas discapacidades mentales y físicas, la ingestión de drogas, bebidas alcohólicas o la simple oposición al acto, afectan el consentimiento. La desigualdad de poder, la distribución jerárquica de roles y la naturalización de la violencia sexual influyen en la falta de percepción. Para este estudio se consideró como victimización sexual directa la que sufren, con base en 
una experiencia particular, las personas víctimas de violencia sexual, la cual puede generar consecuencias para la vida, la salud física, reproductiva y mental, las reacciones conductuales en cualquier ámbito social o comunitario; por su parte, a victimización sexual indirecta ilustra sobre los efectos que provocan, en determinadas personas, el conocimiento sobre actos de violencia sexual que afectan a familiares, amigos, conocidos e incluso desconocidos o que sufren estas personas como consecuencia de la victimización directa en otros, dígase efectos psicológicos, conductuales, generacionales o financieros a nivel social, grupal e individual.

\section{ALGUNOS PUNTOS DE REFLEXIÓN SOBRE LA VIOLENCIA SEXUAL}

Datos fiables reflejan que los delitos más frecuentes en Cuba son los abusos lascivos y las violaciones; que las niñas son las principales afectadas por victimarios hombres, en su mayoría cercanos al ámbito familiar, y que pueden apreciarse relaciones de poder y asimetría con bases en la dependencia económica y la subordinación patriarcal. (Pérez \& Rondón, 2004) ( SEMlac Cuba, 2018)

Algunos datos pueden ser captados directamente del sistema penal, pero este solo hace referencia a los delitos, lo cual no es suficiente para retratar a la violencia como fenómeno global.

Violencia, criminalidad y delito no son conceptos análogos. No toda violencia es delito y no todo delito es violento. La violencia como fenómeno social constituye lo general, abarca acciones $u$ omisiones individuales $y$ colectivas, punibles y no punibles, e identifica un contexto donde confluyen diferentes formas de actuación que individualmente pueden ser calificadas como delito o no, y que subordinadas a un conjunto normativo dan origen a la criminalidad. (Hassemer \& Muñoz, 1989 , p. 27 y 52)

La criminalidad es la suma de todos los delitos que afectan a determinada sociedad; tiene orígenes políticos, económicos y culturales principalmente, y se haya sujeta a la reacción estatal. Desde la perspectiva criminológica, puede subdividirse según las familias de delitos que confluyan o concurran en la generación de determinado fenómeno delincuencial que afecta las relaciones sociales y muestran cierta organicidad como, por ejemplo, la criminalidad económica, la sexual y la convencional o no convencional, entre otras. El delito tiene raíces más específicas, vinculadas a determinantes personales y de riesgo que confluyen en el actuar de victimarios y víctimas, aunque el Estado aparezca colocado al centro de la relación jurídico-penal.

La diferencia entre criminalidad y delito toma significación dentro de la nueva Criminología con el surgimiento de la teoría de la reacción social o labeling approach, (Bergalli, et al., 1983, pp. 146-148) que significó un cambio de paradigma ante el pensamiento criminológico tradicional, de carácter positivista y netamente etiológico; la nueva teoría sugiere que el delito es construido por las agencias de control social y que la verdadera criminalidad es un concepto generalizador del comportamiento considerado antisocial que emerge producto de un proceso de etiquetamiento de los individuos. 
Según Bacigalupo:

El delito, por lo tanto, entendido en el sentido más general de la expresión, será una forma de comportamiento desviado que se considera grave dentro de un sistema social y que es calificado de tal por órganos legislativos con competencia para ello. Lo que caracteriza a todo comportamiento desviado y, por consiguiente, también al delito es su divergencia con los modelos aceptados de conducta, es decir, con los comportamientos que cumplen con las expectativas sociales institucionalizadas. (Bacigalupo, 1996)

El autor de esta investigación estima que el delito sexual tiene una significación valorativa que lo circunscribe al ámbito jurídico, aunque sus rasgos pueden variar atendiendo a su expresión conceptual en las leyes penales sustantivas y al análisis dogmático de sus elementos estructurales. Su contenido será el reflejo de las pretensiones normativas sobre cómo debe ser la conducta humana para no amenazar ni quebrantar los bienes jurídicos que protegen relaciones y derechos de contenido sexual, reproductivo u otros afines.

El delito sexual puede ser considerado aquella conducta que, como expresión de la violencia sexual, integra una figura delictiva prevista en la legislación penal sustantiva, es decir, que se expresa mediante una norma jurídico-penal, generadora de una relación jurídico-penal entre el sujeto que delinque y el Estado, nacida al momento de la comisión del hecho punible. Está constituido por acciones u omisiones, socialmente peligrosas y prohibidas por la ley, que afectan o amenazan de modo significativo la integridad, la libertad e indemnidad sexuales o indican discriminación por razón del sexo o el género, siempre que sean opuestos a la voluntad de las víctimas, menoscaben la sexualidad humana y representen una vulneración de los derechos sexuales y reproductivos. Pueden tener carácter pluriofensivo y aparecer bajo la rúbrica de diferentes bienes jurídicos, por lo que se unen bajo la organicidad que propone la protección de bienes jurídicos generales, dentro de la legislación penal sustantiva.

La necesaria mirada interdisciplinar hacia la violencia sexual se ve afectada por las consecuencias restrictivas que propone el formato legal de los delitos sexuales, ya que reduce la mirada global y obliga a centrarse en aquellos comportamientos que están contenidos en la ley penal, excluyendo el estudio de otras conductas peligrosas cuando no aparecen descritas de forma taxativa; limitando la recolección de datos y el campo de análisis a aquellos procesos ventilados en sede penal, principalmente con resultados condenatorios, y generando una cifra oculta de la criminalidad sexual. Por ende, los delitos sexuales conocidos son siempre menores al fenómeno de la violencia sexual real. Existen datos ocultos que las agencias de control penal no pueden apreciar con su visión parcial y que pasan por un sistema de selección que grosso modo depende de los siguientes factores:

- Visibilización y desnaturalización de la violencia sexual, como facultad para ser percibida y reconocida por víctimas, agresores, familiares, comunidad $y$ sociedad.

- Denuncia, como acto a interés de las víctimas o sus familiares de poner en 
conocimiento institucional tales hechos.

- Conocimiento y confianza en la selección de la autoridad o representante institucional receptor de la información.

- Compromiso para la aceptación y tramitación de la información sobre violencia sexual, sea o no delito.

- Equidad en el análisis desprejuiciado, objetivo y contextualizado de la situación de violencia sexual.

- Protección concretada en la activación de mecanismos de prevención de agresiones sexuales futuras y el amparo a las víctimas.

La ausencia de cualquiera de los elementos descritos afecta la debida protección y la condición de sujetos de las víctimas de la violencia sexual; algunos de estos factores están arraigados a la cultura popular y otros dependen de la actuación institucional, pero todos tienen trascendencia social a niveles macro, exo o micro sistémicos, por lo cual requieren un análisis integral y complejo desde el modelo ecológico.

A lo que se suma que no todos los actos de violencia sexual son reconocidos como tales, lo que depende de cuán arraigados estén los procesos de invisibilización y naturalización de la violencia en la sociedad. De los reconocidos como delitos no todos son denunciados, debido a factores culturales de tolerancia, miedo, vergüenza o impedimentos en el acceso a la justicia. De los denunciados no todos son admitidos y seguidos por las autoridades, ya que dependen de trabas procesales y estereotipos que intervienen en la selectividad del sistema penal.
Las conductas investigadas no siempre culminan en acusación formal ante los Tribunales, ni todas son juzgadas por estos, pues los procesos son judicializados en dependencia de cuestiones técnicas o presupuestos de política criminal, que no siempre responden al análisis contextual del fenómeno que le da origen.

El juzgamiento no garantiza que el proceso termine en sentencia condenatoria; existe la posibilidad que los sancionados en primera instancia sean beneficiados en caso de interposición de recursos ante tribunales superiores y que las sanciones impuestas sean subsidiadas, remitidas o no ejecutadas en su totalidad. Sin contar que la reacción penal es incapaz de remover todos los elementos que condicionaron la violencia.

Otras limitaciones afloran cuando no son cumplimentados los estándares establecidos en los instrumentos jurídicos internacionales sobre el enfoque de género y la valoración de las diferencias. Los delitos sexuales están fundados en múltiples prejuicios sobre la sexualidad humana, donde prevalecen los estereotipos de género y un enfoque sexista que sustenta la condición de sujeto pasivo y la neutralización de la mujer como víctima dentro del proceso penal.

La perspectiva de género sugiere que en la base de la violencia sexual se encuentran una serie de actos discriminatorios y desigualdades sociales que colocan a la mujer en desventaja respecto a la protección de sus derechos que deben ser atendidos de forma interdisciplinar, con un mayor protagonismo del Derecho que regula las relaciones familiares, laborales e interpersonales, previas al ámbito penal. 
El Derecho penal cubano también tiene dificultades para recibir el influjo de las investigaciones socio-criminológicas; carece de una estrategia de complementación interdisciplinar, acciona a efectos de la información que aportan las ciencias naturales y biomédicas, no así de las ciencias sociales; y limita el análisis de la criminalidad sexual a los hechos tratados por los órganos del sistema de justicia penal.

La concreción de estos argumentos evidencia la necesidad de afrontar varios retos criminológicos y jurídicos que contribuyan a visibilizar los procesos de victimización sexual femenina, como medio para su prevención y protección integral.

\section{METODOLOGÍA PARA EL ANÁLISIS DE SENTENCIAS PENALES Y APLICACIÓN DE UNA ENCUESTA DE VICTIMIZACIÓN SEXUAL}

Para la obtención de información actual y confiable se utilizaron varios métodos de investigación teórica. Se revisaron 938 sentencias penales publicadas en 34 Boletines del Tribunal Supremo Popular entre 1974 y el 2016 (último año de publicación), que hacen referencia a 1182 delitos, los cuales se distribuyeron de la siguiente forma:
- Delitos contra los derechos patrimoniales: $354(29.9 \%)$

- Delitos contra la vida y la integridad corporal: 222 (18.8\%)

- Delitos sexuales. Contenidos principalmente en el Título de Delitos contra el normal desarrollo de las relaciones sexuales, la familia, la infancia y la juventud: 166 (14\%)

- Delitos contra la seguridad del tránsito: $104(8.8 \%)$

- Delitos contra la economía nacional: 96 (8.1\%)

- Delitos contra la administración y la jurisdicción: 74 (6.3\%)

- Delitos contra la fe pública: 55 (4.6\%)

- Delitos contra el orden público: 37 $(3.1 \%)$

- Delitos contra los derechos individuales: $33(2.8 \%)$

- Delitos contra la seguridad colectiva: 16 $(1.3 \%)$

- Delitos contra la salud pública: 15 (1.3\%)

- Tráfico de personas: $6(0.5 \%)$

- Delitos contra el honor: $3(0.2 \%)$

- Delitos contra la hacienda pública: $1(0.1 \%)$

La población estudiada estuvo compuesta por 113 sentencias contentivas de 166 delitos sexuales analizados en su contenido fáctico.

Tabla No. 1. Delitos sexuales publicados en los Boletines del Tribunal Supremo Popular.

\begin{tabular}{|c|c|c|c|}
\hline Boletín TSP & Delitos Sexuales & Boletín TSP & Delitos sexuales \\
\hline Ed.Ext.1974 & $\mathbf{1 3}(\mathbf{2 0} \%)$ & 2000 & $\mathbf{4}(\mathbf{3 6 . 7} \%)$ \\
Ed.Ext.1975 & $\mathbf{1 8}(\mathbf{2 6 . 5} \%)$ & 2001 & $\mathbf{2}(\mathbf{6 . 9} \%)$ \\
Ed.Ext.1977 & $\mathbf{1 4}(\mathbf{1 5 . 1} \%)$ & 2002 & $\mathbf{0}$
\end{tabular}




\begin{tabular}{|c|c|c|c|}
\hline II Sem.1978 & $8(12.5 \%)$ & 2003 & $2(12.5 \%)$ \\
\hline II Sem.1979 & $10(14.3 \%)$ & 2004 & $2(6.9 \%)$ \\
\hline I Sem. 1980 & $11(14.3 \%)$ & 2005 & $1(5.9 \%)$ \\
\hline II Sem. 1980 & $15(17.4 \%)$ & 2006 & $7(20 \%)$ \\
\hline I Sem. 1981 & $4(5.9 \%)$ & 2007 & $2(25 \%)$ \\
\hline II Sem.1981 & $7(11.3 \%)$ & 2008 & $1(10 \%)$ \\
\hline Ed.Ext.1985 & $4(8.7 \%)$ & 2009 & $1(5.9 \%)$ \\
\hline Ed.Ext.1986 & $4(18.2 \%)$ & 2010 & $5(17.9 \%)$ \\
\hline 93.Ed ext. 91-92 & $\mathbf{0}$ & 2011 & $4(14.3 \%)$ \\
\hline 1995 & $\mathbf{0}$ & 2012 & $1(4.2 \%)$ \\
\hline 1996 & $3(33.3 \%)$ & 2013 & $2(6.7 \%)$ \\
\hline 1997 & $5(38.5 \%)$ & 2014 & $1(2.7 \%)$ \\
\hline 1998 & $3(25 \%)$ & 2015 & $9(17 \%)$ \\
\hline 1999 & $\mathbf{0}$ & 2016 & $3(9.4 \%)$ \\
\hline & & TOTAL & $166(14 \%)$ \\
\hline
\end{tabular}

Fuente: Ramos, Lázaro E. (2019) Análisis de sentencias en materia penal del Tribunal Supremo Popular.

La distribución total de los delitos sexuales más significativos se expone en la siguiente gráfica: Gráfica No. 1.
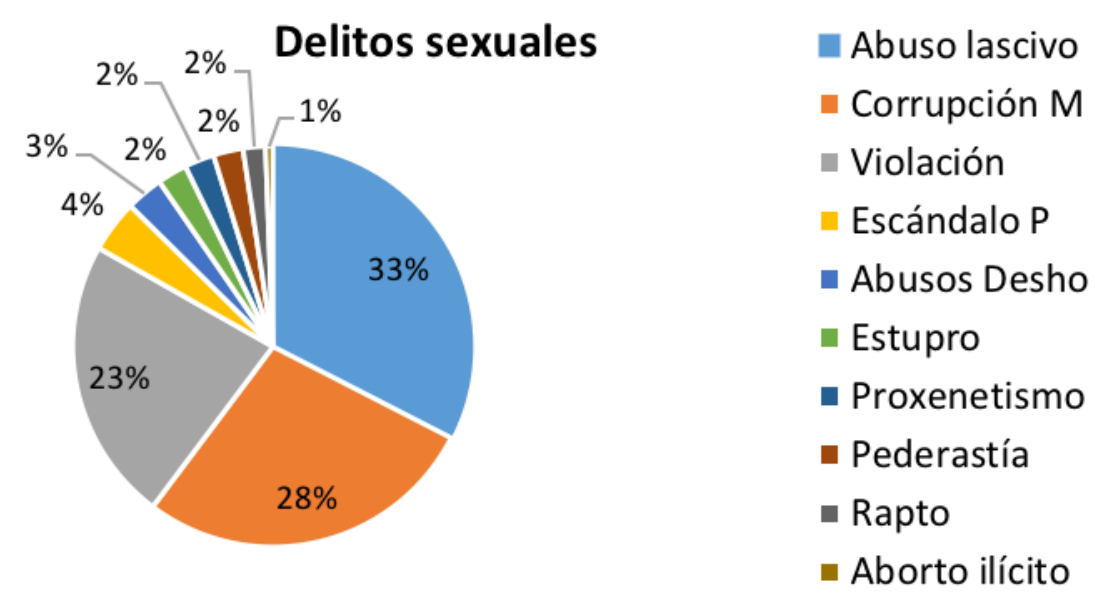

Fuente: Ramos, Lázaro E. (2019) Análisis de sentencias en materia penal del Tribunal Supremo Popular. 
El análisis del contenido fáctico de las sentencias arrojó información sobre edad, sexo, características y antecedentes penales de los acusados; hora, lugar y consecuencias del hecho delictivo; edad, sexo, cantidad y características de las víctimas expuestas en la sentencia y su relación con el victimario; así como otras observaciones pertinentes.

Como el análisis de sentencia solo muestra aquellos hechos que fueron llevados ante los órganos jurisdiccionales, se realizó una Encuesta de Victimización Sexual (EVS) que pudiera corroborar o contradecir los datos obtenidos en la revisión documental. En este caso la muestra estuvo constituida por 211 personas, según selección intencional; $152(72 \%)$ residentes en la provincia de La Habana, 44 (20.9\%) en Granma, 6 (2.8\%) en Matanzas, $4(1.9 \%)$ en Villa Clara, $2(0.9 \%)$ en Mayabeque y $3(1.5 \%)$ de Guantánamo, Artemisa y Holguín; en total distribuidos por 36 municipios de Cuba.

Completando sus características sociodemográficas se pudo constatar que la media aproximada de tiempo viviendo en la misma localidad es de 24.7 años. El 9.5\% de las personas encuestadas Ileva tres años o menos de permanencia en el municipio donde reside, el $90.5 \%$ restante reporta un tiempo de residencia entre 4 y 76 años. La edad de las personas encuestadas oscila entre 18 y 76 años, la media se acerca a 34 años. Las mujeres encuestadas suman $165(78.2 \%)$, los hombres suman 46 para un $21.8 \%$ del total. Las personas solteras suman $128(60.7 \%)$, las casadas $53(25.1 \%)$, divorciadas $26(12.3 \%)$ y viudas $4(1.9 \%)$.
Respecto a las ocupaciones se observa un predominio de personas trabajadoras que suman 120 (56.9\%), 69 estudiantes $(32.7 \%), 11$ jubiladas (5.2\%), 6 amas de casa, consideradas trabajadoras en el hogar (2.8\%), 4 desocupadas (1.9\%) y una discapacitada desvinculada, que suma el $0.5 \%$.

En relación con el nivel de estudios 112 (53.1\%) habían vencido o cursaban estudios universitarios, 63 (29.9\%) habían culminado los estudios preuniversitarios, $24(11.4 \%)$ el nivel técnico, 7 (3.3\%) habían abandonado estudios de nivel medio superior y $5(2.4 \%)$ culminaron los estudios de Secundaria básica.

Los miembros del núcleo familiar que residen con los componentes de la muestra se distribuyen de 1 a 11 personas, siendo la media de familiares de 3.5 miembros por núcleo. La figura masculina como jefe de núcleo familiar aparece en 93 ocasiones, mientras que la figura femenina como jefa del núcleo es mencionada en 78 ocasiones. Del total de las 165 mujeres encuestadas, 39 (23.6\%) se consideraron jefas del hogar, la mayoría solteras y/o divorciadas, del total de 46 hombres encuestados $9(19.6 \%)$ se autoproclamaron jefes. Con relación a la edad de los jefes del núcleo familiar, 65 (el 30.8\%) está entre los 51 y los 60 años, 60 (28.4\%) entre los 41 y 50 años, 33 (15,6\%) entre los 61 y 70 años, 22 (10.4\%) entre 31 y 40 años, 20 (9.5\%) rebasa los 70 años y 11 (5.25\%) está entre los 21 y los 30 años.

En cuanto al nivel económico 67 (31.8\%) miembros de la muestra refieren tener una buena situación económica, 124 (58.8\%) situación regular, y $20(9.5 \%)$ mala situación económica. 
La comparación arroja que los hombres son considerados el principal sostén económico de las familias en el $69.3 \%$ de los casos y las mujeres en el $30.7 \%$. Las mujeres encuestadas que más aportan al sostén económico son el $19.4 \%$ del total de 165 , frente a un $26.1 \%$ del total de 46 hombres encuestados. Los datos generales arrojan que 124 proveedores pertenecen al sexo masculino, principalmente esposos, padres, padrastros y novios de las mujeres encuestadas, mientras que se reportan 55 mujeres proveedoras, en 47 ocasiones las madres de las personas encuestadas. La Encuesta de Victimización Sexual también aportó información sobre: percepción de seguridad y miedo ante la violencia sexual, condiciones que la favorecen, victimización sexual indirecta, directa y reacción social.

\section{ALGUNOS RESULTADOS DEL ANÁLISIS DE LA VIOLENCIA SEXUAL EN CUBA}

La confrontación de información que se extrajo del análisis de sentencias penales juntamente con la Encuesta de Victimización Sexual permitió asegurar que cerca del 93\% de las víctimas de violencia sexual en Cuba son mujeres, con mayor probabilidad de ser victimizadas durante más años de su vida; mientras que en los hombres disminuye el riesgo hacia la adolescencia, subsistiendo en aquellos que tienen afectada la capacidad mental. Esta invariante influye en la percepción de seguridad ya que las mujeres pueden estar expuestas y sentir temor durante mayor tiempo, limitando su calidad de vida. Las mujeres menores de 45 años aseguran grandes probabilidades de ser victimizadas sexualmente en el próximo año.

Las mujeres cubanas perciben inseguridad cuando abordan un transporte con desconocidos y al transitar de noche por lugares de poca iluminación, lo cual está en consonancia con la invisibilización de la violencia real y la mayor difusión de los hechos que ocurren a nivel comunitario y son ejecutados por desconocidos. Sin embargo, los procesos de victimización sexual directa contradicen esa esfera de riesgos y temores, ya que están caracterizados por la agresión de mujeres de poca edad principalmente por victimarios hombres, en su mayoría de edad superior (de entre 14 y 80 años), con un promedio algo superior a los 37 años y con relaciones familiares, de exparejas, de amistad o vecindad, laborales y educacionales con sus víctimas. De ellos solo a un $10 \%$ le constan antecedentes penales por delitos sexuales.

Tabla No. 2.

\begin{tabular}{|l|c|c|c|}
\cline { 2 - 4 } \multicolumn{1}{c|}{} & \multicolumn{3}{c|}{ Relaciones entre víctimas y agresores al momento del hecho } \\
\cline { 2 - 4 } \multicolumn{1}{c|}{} & Sin vinculo anterior & Con vinculo anterior & Total \\
\hline Cantidad de Hechos & 38 & 125 & 163 \\
\hline \% real de Hechos & $23,3 \%$ & $76,7 \%$ & \\
\hline \% según Sentencias & $25 \%$ & $75 \%$ & \\
\hline
\end{tabular}

Fuente: Elaboración propia del autor. (2019) 
El horario de comisión es preferentemente nocturno y los lugares más frecuentes son la casa de la víctima, la del agresor o donde ambos conviven; la revictimización aumenta donde existen relaciones de asimetría o dependencia debido al poder familiar, económico o coactivo del agresor.

Tabla No. 3.

\begin{tabular}{|c|c|c|c|c|c|}
\cline { 2 - 6 } \multicolumn{1}{c|}{} & \multicolumn{2}{c|}{ Relaciones entre agresores y víctimas previas al hecho } & \\
\hline Tipo de Relaciones & Vecindad & Amistad & Familiares & Jerárquica & Total \\
\hline \% real de Hechos & $23,9 \%$ & $10,4 \%$ & $33,1 \%$ & $9,2 \%$ & $76,6 \%$ \\
\% según Sentencias & $24,2 \%$ & $12,9 \%$ & $23,8 \%$ & $14,1 \%$ & $75 \%$
\end{tabular}

Fuente: Elaboración propia del autor. (2019)

En el $45.1 \%$ de los casos las víctimas fueron revictimizadas antes que se articularan mecanismos impeditivos efectivos, consecuencia muy traumática que es casi imperceptible para el Código Penal cubano, debido a la formulación del artículo 11.2. ${ }^{1}$, que resta relevancia a los delitos que afectan derechos inherentes a la persona misma, también conocidos como delitos personalísimos, colocándolos bajo la fórmula del delito continuado (con disminución del marco sancionador) en caso que las diferentes acciones recayeran sobre la misma persona.

1 ARTICULO 11.1. Se considera un solo delito de carácter continuado las diversas acciones delictivas cometidas por un mismo agente que ataquen el mismo bien jurídico, guarden similitud en la ejecución y tengan una adecuada proximidad en el tiempo. En este caso, se aumenta el límite mínimo de la sanción imponible en una cuarta parte y el máximo en la mitad. 2. Cuando diferentes acciones delictivas tienen por objeto derechos inherentes a la persona misma, también tienen el carácter de continuadas y constituyen un solo delito, siempre que afecten a una sola víctima.
Como consecuencias frecuentes se reportaron trastornos psicológicos, miedo, alejamiento de las relaciones sociales, inseguridad y conductas suicidas, mientras que las secuelas físicoreproductivas hacen referencia a la muerte, lesiones, embarazo, transmisión de infecciones sexuales o el VIH - SIDA e infertilidad.

Las personas fueron encuestadas en relación con su conocimiento de actos de victimización sexual y reportaron 163 hechos conocidos por diversas fuentes. La muestra aceptó conocer que en 91 (55.8\%) de los 163 casos se efectuó la denuncia; en $56(34.4 \%)$ ocasiones no se efectuó denuncia y 16 encuestados afirmaron no conocer. Estos datos revelan que la cifra oculta asciende a las dos quintas partes del total de los delitos sexuales cometidos, lo que indica que cada tres delitos denunciados, aproximadamente dos son ocultados al sistema de justicia penal. 
Gráfica No. 2

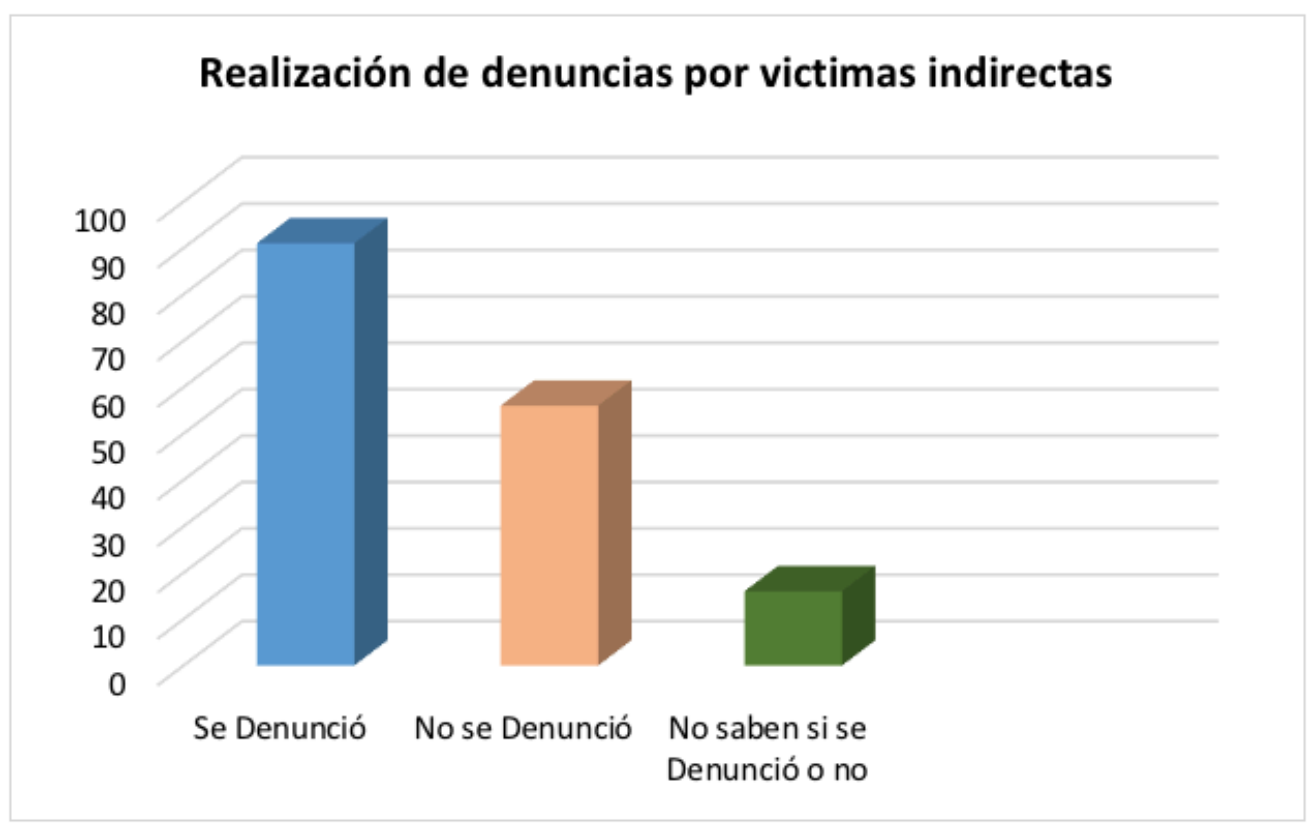

Fuente: Ramos, Lázaro E. (2019) Estudio de victimización sexual.

Sin embargo, la situación es más alarmante aproximadamente tres son ocultados, cuando se colecta la información de las víctimas demostrando que la cifra oculta de los delitos directas, que aceptaron haber sido y hasta ser, sexuales en Cuba es alta y tiene bases machistas en los momentos de la encuesta, victimizadas. ya que el $72.4 \%$ de las mujeres victimizadas no Según su dicho, cada un delito denunciado denunció y el 100\% de los hombres tampoco.

Gráfica No. 3.

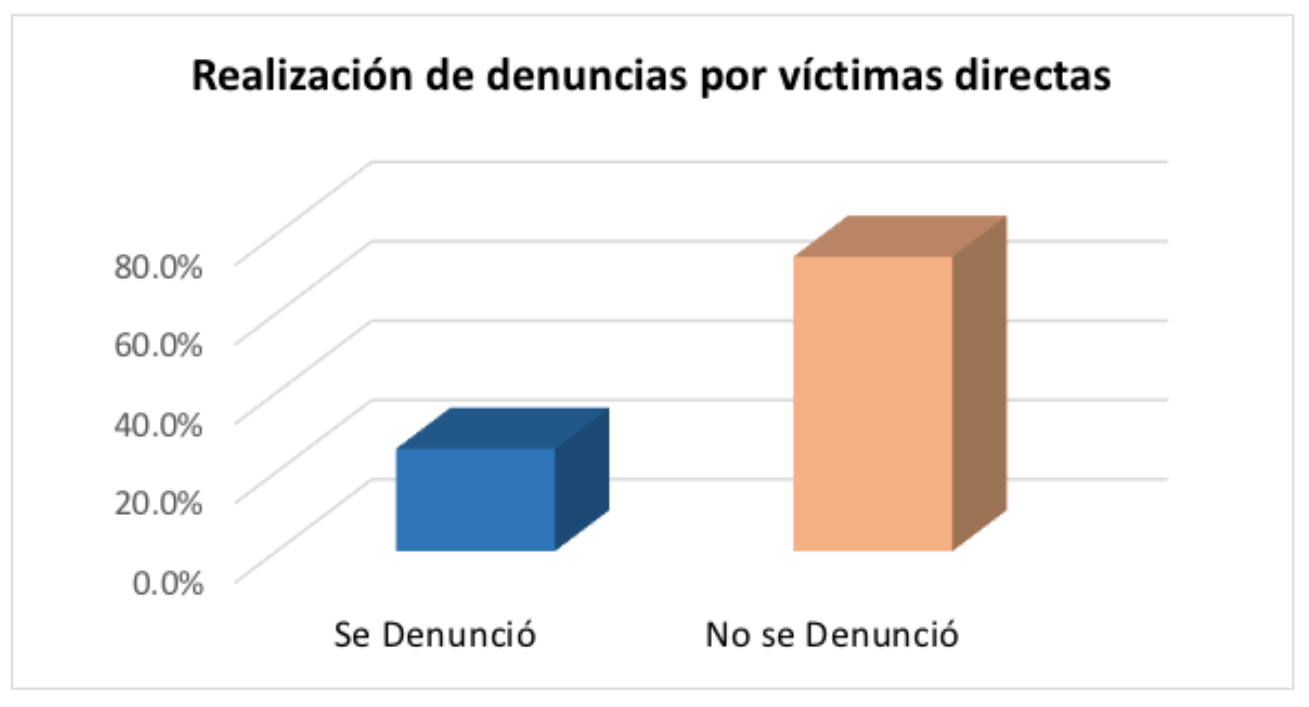

Fuente: Ramos, Lázaro E. (2019) Estudio de victimización sexual. 
Los principales motivos para no acudir a hacer la correspondiente denuncia o poner el hecho en conocimiento de las autoridades se centran en el miedo a las represalias, los prejuicios y la vergüenza de acudir ante tales autoridades, entre muchos otros.

\section{Gráfica No. 4.}

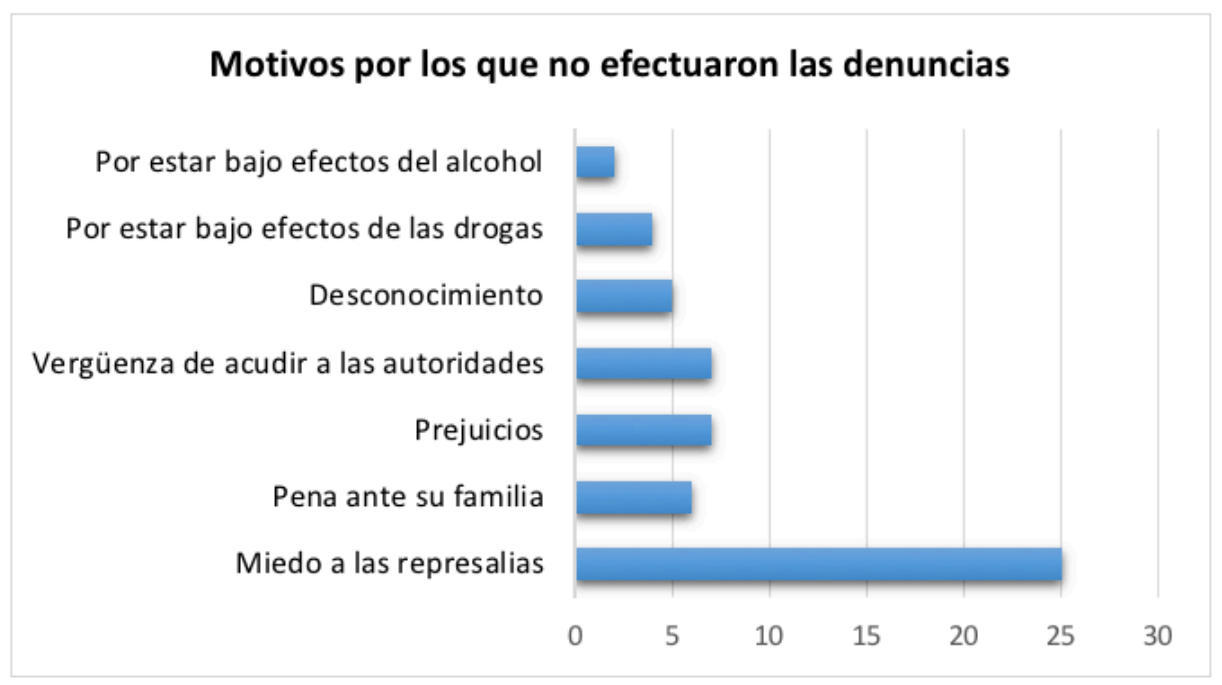

Fuente: Ramos, Lázaro E. (2019) Estudio de victimización sexual.

En términos de reacción social, el delito más reconocido por la muestra es la violación y sus principales denunciantes son las víctimas u otros miembros femeninos de su familia lo que indica que las mujeres están más dispuestas a poner el hecho en conocimiento de las autoridades. Para su punición el 55.9\% consideró apropiada la privación perpetua de libertad, el $21.8 \%$ la pena de muerte, el 19\% la privación temporal de libertad; una persona la sanción de multa y el $2.4 \%$ agregó que debían cortarse sus genitales, lo cual no estaba entre las opciones de respuestas cerradas.

La muestra reconoce la importancia de la educación de niños y niñas para disminuir la violencia sexual, pero luego opta por la utilización de mecanismos de coerción penal reclamando el aumento de la severidad de las penas y el fortalecimiento de la actividad policial. Aprecia efectos de prevención general positiva en el Derecho Penal y el 85.3\% afirmó que las leyes penales eran insuficientes e importantes para aumentar la seguridad de las personas, y el $61.1 \%$ que la violencia requería una ley especial.

Más de la mitad de la muestra confirma el carácter retributivo o especial negativo de las penas; el $58.3 \%$ consideró que eran efectivas para que cada cual tuviera su merecido y sirviera como ejemplo a otros; el $51.7 \%$ estima que son importantes para encerrar a las personas peligrosas.

Solo el 34.6\% la consideran importante para atemorizar a las personas ante la violación de la ley, por lo cual el $65.4 \%$ desconfía de sus efectos de prevención general negativa. 
El porciento más bajo se encuentra en la credibilidad de los efectos correctores, pues solo el $25.1 \%$ cree que las penas sirvan para corregir o readaptar a los delincuentes sexuales, poniendo en dudas la función de prevención especial positiva y el carácter resocializador de estas.

Los encuestados otorgan mayor relevancia y peligrosidad al consumo de drogas y alcohol como factor individual desencadenante de la violencia sexual, que al resto de los componentes estructurales y culturales que la condicionan.

\section{DE LAS LIMITACIONES JURÍDICAS Y SUS EFECTOS}

Las limitaciones jurídico-penales se relacionan con la neutralización y despersonalización de las víctimas. Ofrecen una idea de cómo reacciona el Estado ante los deberes de garantizar el acceso a la justicia y de actuar con la debida diligencia para prevenir, investigar, sancionar y reparar por actos de violencia sexual contra la mujer. Entre ellas destacan la falta de obligatoriedad de la denuncia por los facultativos que atienden las consecuencias psicológicas o menos objetivas de la violencia sexual, dado el carácter restrictivo del artículo 162; los impedimentos legales que introduce el requisito de procedibilidad del artículo 309, ambos del Código Penal, basado en antiguas concepciones sobre la intimidad; y la restricción comunicacional de los delitos sexuales que predomina en los Boletines del Tribunal Supremo Popular desde el año 2004.

Los servicios de Salud Pública constituyen una fuente de reconocimiento de la violencia sexual, pero no son suficientes para dar traslado al sistema de justicia penal, pues determinadas cuestiones éticas de la profesión médica se contraponen a la obligatoriedad de la denuncia. Según el artículo 162 sobre los médicos cubanos recae una obligación expresa de denunciar cuando «notan u observan signos de lesiones externas por violencias o indicios de intoxicación, de envenenamiento o de haberse cometido cualquier delito», sin embargo, la obligación no alcanza siempre a la violencia sexual.

En los servicios de urgencia de los hospitales permanece una guardia policial que toma referencia de las lesiones que presentan los pacientes y su vinculación con algún hecho delictivo y aseguran la emisión del Certificado. El agente puede tener participación en la denuncia. En el caso de violencia sexual no existe la misma participación y el facultativo es quien determina, mediante reconocimiento físico o psicológico, si hay elementos para presumir un delito, cuya denuncia queda a voluntad de la víctima y/o su familia.

El sistema penal, en su estructura tradicional, está preparado para actuar en función de consecuencias físicas objetivas y perceptibles, aptas para ser investigadas por las ciencias médicas y naturales, sin embargo, tiene una visión reducida de los elementos que aporta el enfoque social en salud. Cuando los efectos consisten en afectaciones a la salud mental, problemas conductuales e intergeneracionales, que deben ser atendidos por psicólogos u otros servicios de orientación, los mecanismos específicos que obligan a la denuncia están limitados. 
La desconexión asistencial entre el sistema de salud, la prevención y la atención de la violencia sexual fue corroborada por la unidad muestral, pues el 36\% estimó que los servicios inadecuados de Salud Pública no favorecían la violencia sexual y el $41.2 \%$ que solo favorecía un poco. Estos datos contradicen el esfuerzo internacional por demostrar que la violencia es un tema esencial en las políticas de salud, lo cual puede ser el resultado de una mala estrategia de comunicación social y visibilización de las violencias.

Las consecuencias menos visibles aparecen como efectos colaterales y presupuestos de desvalor de las conductas violentas, elementos intangibles que cimentan el análisis de la peligrosidad social de los delitos sexuales. La perspectiva de género y generacional en el Derecho y el enfoque social en Salud contribuyen a la visualización de estos efectos y aportan elementos para la reacción social oportuna.

Otra gran dificultad que enfrentan las investigaciones sobre criminalidad sexual en Cuba es la carencia de denuncias. Los problemas que impiden su realización son apreciados por el sistema penal patriarcal como propios de la libertad individual en el ámbito privado, y ante ellos se repliega en sus funciones; algo que no ocurre con la mayoría de los ilícitos penales, que son de acción y persecución pública sin excepción.

La Encuesta de Victimización Sexual mostró que el nivel bajo de denuncias en Cuba obedece al miedo a las represalias, prejuicios y sentimientos de pena o vergüenza ante las autoridades $y$ los familiares, o porque la víctima se siente responsable cuando ha ingerido alcohol o drogas previamente al hecho. Esta realidad se ve reforzada por el impedimento legal que representa la condición de procedibilidad que aparece en el artículo 309.1 y 2 del Código Penal vigente. ${ }^{2}$

Este requisito impide que el proceso penal transforme la punibilidad en pena, al negar la persecución pública de los ilícitos contra el normal desarrollo de las relaciones sexuales y la familia a los que hace referencia; otorga relevancia a la intervención privada y limita la denuncia abierta en los delitos de violación, la pederastia con violencia, los abusos lascivos, el incesto y el estupro, solo cuando produzcan escándalo; siendo esta una circunstancia poco frecuente en los delitos sexuales, caracterizados por el silencio.

En estos delitos semipúblicos o de previa instancia de un particular, el requisito legal impide denunciar a la pareja de las víctimas cuando las relaciones sean de orientación

$2 \quad$ Artículo 309.1. En los delitos de violación, pederastia con violencia, abusos lascivos, incesto, bigamia y matrimonio ilegal, es necesario, para proceder, la denuncia de la persona agraviada, cualquiera que sea su edad, o la de su cónyuge, ascendientes, hermanos, representante legal o persona que la tenga bajo su guarda y cuidado, salvo en los casos que hubieran producido escándalo, en los que basta la denuncia de cualquier persona.

2. En el delito de estupro solo se procederá por denuncia del representante legal de la persona agraviada. No obstante, si el denunciante desiste de su denuncia, por escrito y en forma expresa antes del juicio o verbalmente y dejando constancia en acta durante su celebración, se archivarán las actuaciones. 
homosexual o de noviazgo, a los descendientes u otros familiares colaterales, vecinos, amigos, compañeros de estudio o trabajo, por tanto, aflora que la relación que prevalece entre los autorizados legalmente a denunciar $y$ las víctimas de tales delitos es generalmente asimétrica, con elementos distintivos de poder y autoridad decisoria familiar de los posibles denunciantes, ejercida por el cónyuge, los ascendientes, los hermanos y el representante legal o persona que la tenga bajo su guarda y cuidado.

El control patriarcal de la sexualidad femenina se apoya en antiguas concepciones sobre la privacidad y la intimidad, y justifica la desigualdad jurídica en la persecución penal de varios delitos desde la propia norma jurídicopenal. Con este requisito la ley penal condiciona el surgimiento de la relación jurídico-procesal, porque crea mecanismos de invisibilización de la relación jurídico-penal que le da origen, negando la obligación del Estado a conocer e investigar todo ilícito punible e introduciendo una excepción por inacción ante hechos ocurridos en el supuesto "ámbito privado".

En el caso del apartado 2 del artículo 309, es relevante que sea el representante legal quien tenga la potestad de establecer la denuncia por Estupro y también de desistir de ella, sin importar el criterio de la víctima, Ilamada "persona agraviada". La discriminación surge con los orígenes del propio delito, concebido para proteger el honor del padre de la agraviada, lo cual trasciende hasta nuestros días y se reafirma cuando el delito, que constituye esencialmente un acto de carácter sexual, sigue recogiéndose bajo la rúbrica de los "Delitos contra el normal desarrollo de la familia", lo que es una dificultad en la organización dogmática, porque desnaturaliza el bien jurídico individual que pretende proteger.

El requisito de procedibilidad también dificulta la persecución penal en caso de que los hechos pretendan ser puestos en conocimiento por vías indirectas, o sea, mediante comunicación telefónica, carta, documento anónimo o autografiado, correo electrónico, entre otros medios. Los prejuicios morales en los elementos socio-jurídicos restringen la denuncia de los delitos sexuales y el debido acceso a la justicia.

El análisis de las sentencias también evidenció la forma en que los prejuicios y estereotipos influyen en los medios de comunicación de la actividad jurisdiccional, pues hasta el año 2003 los Boletines del Tribunal Supremo Popular expusieron los elementos fácticos que motivaron las resoluciones judiciales sin referir el nombre de los participantes. A partir del año 2004 aparece una fórmula expositiva que pasa a ser utilizada permanentemente desde el año 2010, limitando el conocimiento público de los hechos probados, la cual plantea: "Que se da por reproducido el hecho declarado probado por el tribunal de instancia, pues su conocimiento no resulta indispensable para la resolución del recurso." Y así deja de narrar hechos delictivos que afectan a la sociedad cubana y que tampoco tienen carácter público porque suelen ser resueltos en juicios orales a puertas cerradas.

Resulta lógico que se proteja la información sobre agresores y víctimas e incluso ciertas condiciones detiempoy lugarqueindividualizan 
el acto delictivo; pero no debe omitirse el hecho cierto. Con esta decisión, el único medio de comunicación social de la actividad jurisdiccional vuelve a dirigir al ámbito de la privacidad los ilícitos de contenido sexual, coarta la prevención situacional y olvida la necesidad de protección de las futuras víctimas directas e indirectas de la violencia sexual.

\section{PROPUESTA CONCLUSIVA}

Es un deber personal e institucional promover la visualización y desnaturalización de la violencia sexual contra la mujer e implementar un proceso sistemático de construcción del conocimiento sobre la violencia y la criminalidad sexual, con enfoque de género, que facilite la apreciación de la posición desfavorecida de las mujeres y las condiciones estructurales, culturales y personales que confluyen en su victimización. Para su concreción puede valorarse la posibilidad que se implemente un sistema de atención integral para víctimas de violencia sexual de cualquier edad, que observe más allá de los efectos físico-reproductivos. Que se divulgue, a través de los Anuarios de Salud u otras publicaciones periódicas, datos estadísticos sobre la cantidad de exámenes medicolegales realizados por provincias y las consecuencias físico-reproductivas y psicológicas de la violencia sexual.

Debe instituirse una estructura funcional intersectorial que desarrolle la factibilidad organizacional, apoye y facilite la difusión de las investigaciones científicas jurídicas y socio-criminológicas, con vistas a su posible implementación legislativa y la utilización en la toma de decisiones político-criminales que tiendan a suprimir la neutralización y despersonalización de las víctimas en el sistema de justicia penal y para esto deben desarticularse las barreras que dificultan el acceso a la justicia.

Debe valorarse la posibilidad de instar a la obligación de denunciar a los facultativos que conozcan de indicios de violencia sexual durante el servicio de salud ampliando el contenido del artículo 162 y suprimir el requisito de procedibilidad del artículo 309, ambos del Código Penal cubano, dado su carácter sexista y las dificultades prehistóricas que propone a la persecución penal de los delitos sexuales.

El Tribunal Supremo Popular debe analizar las causas del retroceso en el área comunicacional y los beneficios de introducir nuevamente en los Boletines los supuestos fácticos de las Sentencias que versan sobre Delitos contra el normal desarrollo de las relaciones sexuales, la familia, la infancia y la juventud.

Como respuesta a un reclamo que subyace en parte de la población cubana se puede afrontar la elaboración de una ley contra las violencias, que no sea penal, pero revele los procesos discriminatorios en todos los ámbitos de expresión; desmitifique el espacio privado; inste a garantizar la equidad en la toma de decisiones; introduzca métodos alternos de gestión de los conflictos; inserte la perspectiva de género en todo análisis de las violencias; facilite la intervención activa de las víctimas en los procesos investigativos; permita la visión interdisciplinar y desarrolle métodos de heterointegración en el orden civil, de familia y administrativo; involucre nuevos actores 
sociales; resalte las facultades discriminantes de las condiciones estructurales y culturales; y muestre el deber estatal de garantizar la descongestión de la ruta crítica para sus víctimas.

Si no es posible tener leyes mejores que las pretendidas, bástenos con ahondar en la Criminología, multiplicar las voces y seguir al Maestro José Martí, cuando decía: «La palabra. Solo cuando justa, vence».

\section{TRABAJOS CITADOS}

SEMlac Cuba, 2018. Violencia sexual: Impactos ocultos. Género y Comunicación, XIII(11).

Bacigalupo, E., 1996. Manual de Derecho Penal. Parte General. Bogotá: Temis.

Bergalli, R., Bustos, J. \& Miralles, T., 1983. El pensamiento criminológico I. Un análisis crítico. Bogotá: Temis.

Bernabeu, N., 2017. Lecciones aprendidas en la prevención y atención de la violencia contra las mujeresen la región. En: Violencia de Género, Prostitución y Trata de personas. La Habana: CENESEX.

García-Moreno, 2005. Estudio multipaís de la OMSsobre salud de la mujer y violencia doméstica contra la mujer: primeros resultados sobre prevalencia, eventos relativos a la salud y respuestas de las mujeres a dichas violencias, Ginebra: OMS.

Hassemer, W. \& Muñoz, F., 1989. Introducción a la Criminología y al Derecho Penal. Valencia: Tirant lo Blanch.

Pérez, E. \& Rondón, I., 2004. Violencia, familia y género: reflexiones para la investigación y acciones preventivas. Sexología y Sociedad, 10(26).

Tjaden, P. \& Thoeness, N., 2000. Prevalence, incidence and consequences of violence against women: findings from the National Violence against Women Survey. NCJ.

\section{Lázaro Enrique Ramos Portal}

Afiliación: Universidad de La Habana, Cuba.

Profesor, investigador y abogado. Doctor en Ciencias Jurídicas, Máster en Criminología, Licenciado en Derecho por la Universidad de La Habana. Candidato a Doctor en Criminología por la UANL, México. Profesor principal de año académico. Segundo jefe del Departamento de Ciencias Penales y Criminología. Miembro de la Academia Latinoamericana de Derecho Penal y Penitenciario (ALDP) y del Consejo Latinoamericano de Ciencias Sociales (CLACSO). Correo de contacto: Iramosportal@gmail.com 
